\title{
Optimization of Energy Consumption in DXAC using MATLAB/SIMULINK for Improved Performance and Thermal Comfort
}

\author{
Ramesh S $\mathrm{P}^{\dot{\mathrm{A}}^{*}}$ and Emran Khan $\mathrm{M}^{\dot{\mathrm{A}}}$

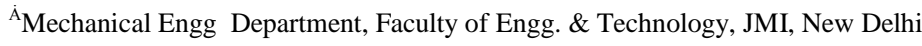 \\ Accepted 10 January 2014, Available online 01 February 2014, Special Issue-2, (February 2014)
}

\begin{abstract}
Energy consumption in the built environment has become a significant issue on a global scale. Escalating energy costs and environmental concerns have made energy use optimization a viable option for buildings. With more number of commercial office buildings coming up, requiring large amount of energy in Heating Ventilation and Air Conditioning system amounting to nearly $30 \%-40 \%$, there is an urgent need to mitigate this ever increasing energy crisis. The goal of energy modeling of HVAC is to accurately predict the energy use to test the energy performance of HVAC system with regards to an established standard and reduce the energy consumption in order to find the resulting energy savings. This paper deals with reducing energy consumption by optimizing the variable speed motor run air cooled Direct Expansion Air Conditioner by modeling and simulation using MATLAB/SIMULINK. in a commercial building for Indian climatic condition. The simulation results indicate that variable-speed fan control strategy contributing to most of the savings. This has resulted in considerable energy saving with improved performance of the DXAC system without compromising the occupants comfort level.
\end{abstract}

Keywords: Direct Expansion Air Conditioner, Energy, commercial building, MATLAB/SIMULINK, simulation, modeling

\subsection{Introduction}

Continuing increase in the global electricity demand and depletion of fossil fuel resources have necessitated a paradigm shift in the development of energy-efficient technologies. Summer air-conditioning is significantly contributing to the peak electricity demand, affecting the cost of maintaining a reliable electricity supply, and hence remains a challenging problem. Rising energy prices and present environmental concerns and the rising human requirement for solutions with better comfort and lower costs have resulted in an increased awareness for the energy use in the built environment. Buildings are the most complex and dynamic systems designed to cater to human comforts. They have to function efficiently and stay healthy by maintaining all the building services within healthy range Building are the most energy consuming systems that man has ever created. $40 \%$ of the total energy is used in buildings. $16-20 \%$ of primary energy is used is used in buildings in developing and developed world.

Technical advances in building structural systems and materials, heating and other comfort-providing systems and controlling strategies all lead to the integration of building technology with the function of buildings and the aesthetics. Therefore, in the process of improving the performance of energy systems and increasing the energy efficiency, integrated system approaches are of high

*Corresponding author: Ramesh S P importance. Performing the necessary energy analysis before any construction installation occurs can help designers and decision makers reach guided solutions. Hence, a broad range of calculation tools for evaluating the operation of energy systems and the controls in buildings have been developed the latest years with different levels of complexity and angles of focus.

Worldwide, buildings are responsible for over $40 \%$ of energy consumption and similar percentage of green house gas (GHG) emissions. With ever rising population and demand for energy use in buildings developing countries like India, china, Brazil and South Africa have to take giant step to reduce over reliance on world's depleting fossil reserves and mitigate GHG emissions for a better future. With increase in IT service sector, over $70 \%$ of construction yet to take place in 2030, India poised to meet one of the biggest challenges of rising demand for electricity. Among the building services, heating ventilation and air conditioning (HVAC), lighting, fans and pumps and security are the major energy consuming systems. Effective control of these services will ensure desired comfort conditions and efficiency improvement. The operation of the vapor compression cycles in air conditioning units of small size is frequently accomplished with the aid of On/Off temperature control of the return air. In such equipments, this kind of control presents unsatisfactory performance in relation to the thermal comfort and the energy efficiency. Packaged airconditioners and heat pumps serve over $60 \%$ of the 
commercial building floor space in the U.S., contributing to about 230 trillion Btus of energy consumption annually. Therefore, even a small increase in operational efficiency of these units can lead to significant reductions in energy use and carbon emissions. A number of control strategies that can be implemented in a controller, which can be retrofit into an existing unit, to improve the operational efficiency of packaged heating, ventilation and airconditioning (HVAC) equipment. This technical paper demonstrates a systematic method of modeling and simulation of the most common Direct Expansion air conditioning (DXAC) system found in office and residential buildings for single floor. Obviously, these are not the only components met in the cooling system. Numerous pieces of equipment, as piping, circulating pumps, expansion tanks, zone valves, relief valves and other essential elements are needed to make a safe and functional cooling system. However, this study focuses on the analysis of the chosen reference system. Earlier several models have been developed in the computational tools of MATLAB/SIMULINK.

There are many studies on how the different control strategies can reduce the HVAC energy consumption. Also several studies have been developed for optimal control of HVAC systems. Braun et al. proposed a methodology for determining the optimal control strategy for an HVAC system in which they showed that the energy consumption of a cooling plant can be represented in terms of the controlled and uncontrolled variables by a quadratic cost function. Their method allowed a rapid determination of near-optimal control setting over a range of conditions. Ahn and Mitchell used this methodology for a central cooling plant and illustrated the optimally-set temperatures for supply air, chilled water and condenser water, to be selected such that energy consumption is minimized under a range of uncontrolled variables. Yao et al. describes a mathematically optimal operations of a large cooling system based on an empirical model for chilled water cooling systems and showed that $10 \%$ energy savings were possible by applying the optimal model to a residential cooling system. Huh and Brandemuehl suggested a method for optimization of a DX air conditioning system to minimize energy with a special emphasis on the control of humidity in commercial buildings. They showed that the most significant factors affecting the system operations are the interaction between the compressor capacity control and the supply air fan control.

The effect of different HVAC optimized control strategies on energy consumption in an actual typical air conditioning system was explored by Ghaddar et al. The simulation results demonstrated that varying the supply air temperature and fresh air flow rate will result in a decrease of $11 \%$ of the total operational energy cost. Yan et al. illustrated an adaptive optimal control model for building cooling and heating sources

\subsection{Description of DXAC}

Present study is focused on DXAC system which has air cooled condenser normally used for single floor in residential and office buildings. The block diagram of DXAC is as shown below.

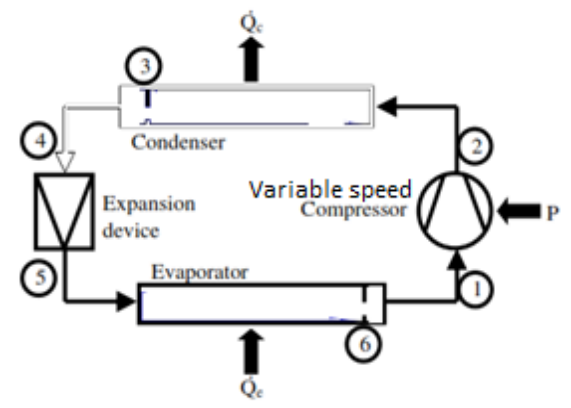

Figure 1. Basic vapour- compression cycle components

In direct expansion or DX types of air conditioning plants, air used for cooling space is directly chilled by the refrigerant in the cooling coil of the air handling unit Since the air is cooled directly by the refrigerant the cooling efficiency of the DX plants is higher. However, it is not always feasible to carry the refrigerant piping to the large distances hence, direct expansion or the DX type of central air conditioning system is usually used for cooling

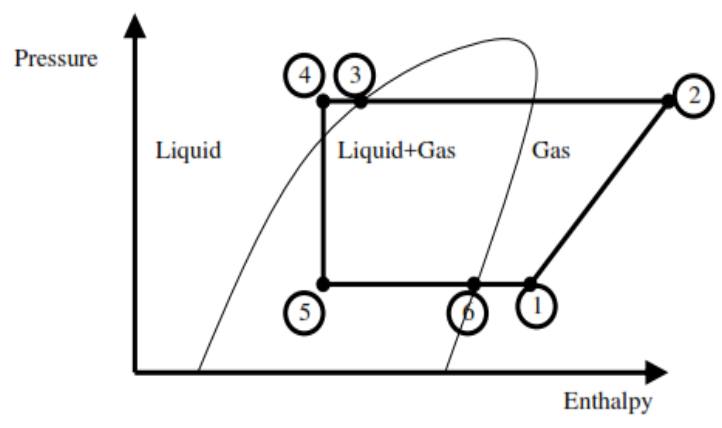

Figure 2. The basic vapour- compression cycle (P-h diagram)

the small buildings or the rooms on the single floor. For heat pumps the main idea is to use the heat rejected in the condenser (refrigeration applications the focus is on the heat transferred to the evaporator (order to compress gas, work has to be done. The energy for those works comes from the power supplied to the compressor. In order to establish a heat transfer rate into the evaporator, the evaporation temperature has to be lower than its surroundings. In the same way, the condensation temperature has to be higher than its surroundings. This means that the temperature of the condenser has to be higher than the temperature of the evaporator. The temperatures at which gasses condense (dew point) and liquids evaporate (bubble point) are substance specific and depend solely on the pressure. Therefore the temperature of the evaporator and the condenser can be controlled by controlling the pressure in the evaporator and condenser. In order to maintain a higher pressure in the condenser than in the evaporator, two more components are needed. The compressor is placed at the outlet of the evaporator, while an expansion device is placed at the inlet of the evaporator. These four components form the basic vapour compression cycle. The following will explain the purpose of each of them. 
DXAC in its simplest form consists of four basic components; compressor, condenser, expansion valve and evaporator. In this system compressor, condenser and evaporator fans are variable speed. The complexity of the air conditioning control comes from the non-linear nature of the process, the strong correlation between the two most important controlled variables (the air humidity and temperature) and the restrictions imposed in the control strategy for the external and internal desired conditions. Provision of variable speed system improves the energy performance along with energy saving depending upon the cooling load demand in the evaporator. As per the available research majority of the energy consumption occur at continuous running of fans in condenser and evaporator irrespective of the cooling requirement. Any regulation on continuous running of fans and compressor motor as per the cooing load demand, there is substantial energy saving along with reduced maintenance of motors and fans.

\subsection{Modeling \& simulation of DXAC system using MATLAB/simulink}

Modeling is the generation of mathematical equations used to describe the response of dynamic processes. Usually this is done by describing the system using well known balance laws (e.g. the law of conservation of mass). Then these equations are Laplace transformed so that the system can be described in the s-plane as a transfer function. A transfer function is a function that describes how an input signal transfers through a device (e.g. a valve or a pipe) and becomes the output signal. More about transfer functions can be read in. When a physical system has been modeled it can be simulated using a designated program, e.g. Matlab. Simulating a model is an easy and fast method to show how the model responds to inputs. For instance the response of a process excited by a step response may be simulated on a computer in a matter of seconds; while in real time it might take several hours or days before the systems settles. Thus, one of the most important reasons for using mathematical models is that it has the potential of saving a great deal of money. By running tests on a computer it is easier and faster to correct undetected errors before the system is implemented into the real system. It is also safer to run tests on the model rater than on the actual system. Another important reason why mathematical modeling is important and has become as popular is that modern controllers can utilize the information from the models. This information can be used to filter away the disturbance from the control signals in order to reduce wear and tear (e.g. Kalman lter). Or it can be used to calculate estimates of future outputs in order to generate more optimal control signals (i.e. MPC ) than the traditional PID-controller. Also, to be able to control certain processes, a model based on the actual physical system is necessary.

\subsection{Mathematical modeling of DXAC}

\subsubsection{Compressor}

Starting at the state point 1 in Figure 2-1 the refrigerant just left the evaporator in the state of a slightly superheated gas at low pressure. The compressor takes in the gas, compresses it, and discharges it at a higher pressure. In the ideal case the compression is a reversible and adiabatic process. The work done by the compressor therefore becomes

$\mathrm{Qc}=\mathrm{mc}\left(\mathrm{h}_{2}-\mathrm{h}_{1}\right)$

Where $\mathrm{m}$ is the mass flow rate and $\mathrm{h} 1$ and $\mathrm{h} 2$ are the specific enthalpies at state point 1 and 2, respectively. The function of the compressor ensures a constant flow of refrigerant through the system. The compressor is also the part of the system where energy has to be applied/ converted.

\subsubsection{Condenser}

After compression, the refrigerant has a high pressure (State point 2) and is pushed through the condenser. While it is flowing through the condenser, the refrigerant rejects heat \& Qc to the surroundings and condenses.

Qcond $=$ mcond $\left(\mathrm{h}_{2}-\mathrm{h}_{1}\right)$

Where mcond is the mass flow rate in condenser, $\mathrm{h}_{2} \& \mathrm{~h}_{1}$ are the enthalpies. The last part of the condenser (State point 3-4) is used for sub cooling i.e. cooling the liquid below its bubble point temperature. The sub cooling ensures that no vapour will leave the condenser. Vapour flowing to the expansion valve will disturb the flow through the expansion device and thereby decrease the flow rate through the evaporator.

\subsubsection{Evaporator}

Right after the expansion device (State point 5) the refrigerant enters the evaporator, where the evaporation takes place. The heat needed for evaporation is taken from the evaporator's surroundings.

$\mathrm{Qe}=\operatorname{meva}\left(\mathrm{h}_{1}-\mathrm{h}_{6}\right)$

Where meva is the mass flow rate of air in the evaporator. h1 \& h6 are the enthalpies. The last part of the evaporator (State point 6-1) is used for superheating i.e. heating the vapour above the dew point temperature. The superheating ensures that no liquid will leave the evaporator and thereby enter the compressor where it can cause damage. On important point here is that the heat transfer coefficient is smaller for gas than for liquid. Therefore efficiency decreases with increasing superheat. A balance has to be found between evaporator stability (high superheat) and system efficiency (low superheat) and the compressor needs to be protected against liquid in the inlet (high superheat). The superheated gas at low pressure is now ready for compression again and the cycle repeats itself. The challenge using this cycle is to get the needed refrigeration capacity (refrigeration system) or heating capacity (heat pump) using a minimum of power

\subsubsection{Coefficient of performance (COP)}


A measure for the energy efficiency of a refrigeration cycle is the COP. For a cooling system the COP can be expressed as

$\mathrm{COP}=\mathrm{Q} / \mathrm{W}$

Improving COP implies therefore either increase cooling capacity or decrease the compression work

\subsubsection{Expansion device}

When reaching the expansion device the refrigerant is a liquid at high pressure (State point 4). While it flows through the expansion device, the pressure is dropped from the condensing pressure to the evaporation pressure. This pressure drop causes the refrigerant to start evaporating.

Expansion valves can either be operated manually, electronically (EXV) or thermostatically (TXV). The input signals are the same for all of them, namely the evaporation pressure and the temperature of the vapour leaving the evaporator. In order to operate the manual valve, someone has to read the temperature and the pressure on gauges and change the setting of the valve by turning a handle. The EXV gets the input from sensors, calculates an opening degree and uses a small motor to adjust the opening area of the valve. The TXV converts the temperature signal to a pressure and the opening degree of the valve is determined by equilibrium of pressures. The choice between TXV and EXV has to be made from application to application. In general it can be mentioned that a TXV solution is cheaper than the EXV solution. On the other hand the EXV is more flexible regarding changing of characteristics. EXV solutions are common on large systems whereas TXV solutions are more common on small systems.

On many systems TXV and EXV will perform equal, which does not justify the rather expensive EXV solution. Nevertheless there are systems where EXV's perform better than TXV's and the extra cost can be justified. But for the time being, there are no indicators that the market will turn its back on TXV's. From today's point of view there are reasons to believe that TXV's will stay in the market on a large scale.The refrigerant flow through the EEV is represented by an orifice equation and its mass flow rate is calculated:

$\mathrm{mr}=\mathrm{C}\left(\pi \mathrm{D}^{2}\right) / 4 \sqrt{ } 2 \rho\left(\mathrm{P}_{1}-\mathrm{P}_{2}\right)$

where $\mathrm{D}$ is the orifice diameter, $\rho$ is the refrigerant density, $\mathrm{P}_{1}$ is the upstream pressure, $\mathrm{P}_{2}$ is the downstream pressure and $\mathrm{C}$ is the mass flow coefficient, which is a function of the EEV geometric parameters and the refrigerant thermodynamic properties.

The objective function is to minimize of the overall power consumption of the whole system with controlled variables being $\mathrm{mr}$ and $\mathrm{T}_{\text {sup. }}$. The power consumption obtained from the compressor, evaporator fan, and condenser fans is given as:

$\mathrm{P}_{\text {total }}=$ Pcomp + Pcond + Peva
Optimal power and temperature can be obtained by solving equations (7)

$\partial \mathrm{P}_{\text {total }} / \partial \mathrm{m}_{\mathrm{r}}=0, \partial \mathrm{P}_{\text {total }} / \partial \mathrm{T}_{\text {sup }}=0$

\subsection{Constraints}

\section{Constraint 1}

The building cooling load $\mathrm{Q}_{\mathrm{b}}$ must be less than the cooling capacity of the DX plant

$\mathrm{Q}_{\mathrm{b}}<\mathrm{Q}_{\mathrm{e}}$

\section{Constraint 2}

The interactions between the evaporator, air-cooled condenser and the compressor formulate a constraint as:

$\mathrm{Q}_{\mathrm{rej}}=\mathrm{P}_{\text {comp }}+\mathrm{Q}_{\mathrm{e}}$

\section{Constraint 3}

Supply air temperature is restricted by

$10 \mathrm{C} \leq \mathrm{T}_{\text {sup }} \leq 20 \mathrm{C}$

Constraint 4

The refrigerant mass flow rate through the DX air conditioning system should be within its limitation

$\mathrm{m}_{\mathrm{r}} \min \leq \mathrm{m}_{\mathrm{r}} \leq \mathrm{m}_{\mathrm{r}} \max$

\section{Constraint 5}

The comfort ranges for the indoor air temperature $\mathrm{Tz}$ and relative humidity $\mathrm{RHz}$ during occupied periods are given by

$22 \mathrm{C} \leq \mathrm{T}_{\mathrm{z}} \leq 26 \mathrm{C}$
$40 \% \leq \mathrm{RH}_{\mathrm{z}} \leq 60 \%$

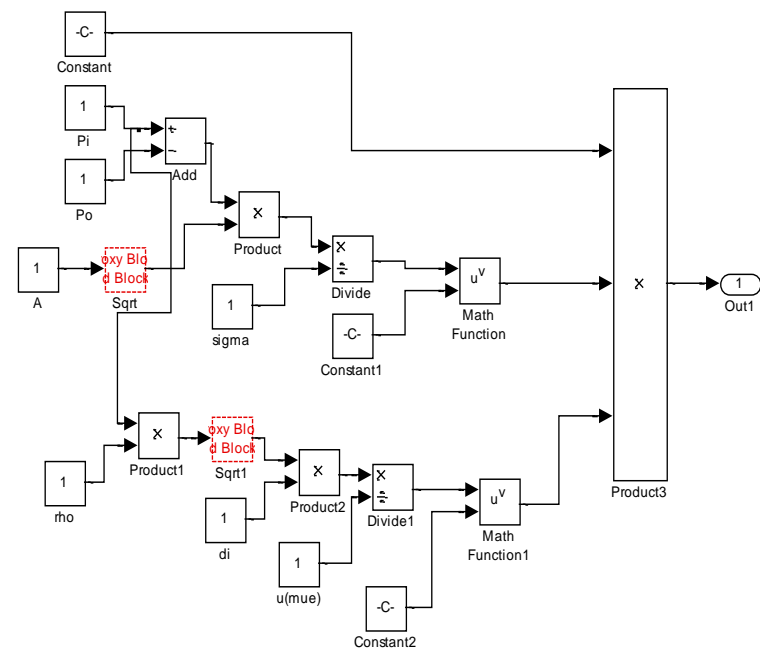

Figure 3. Simulink model of 
Refrigerant mass flow rate through EEV

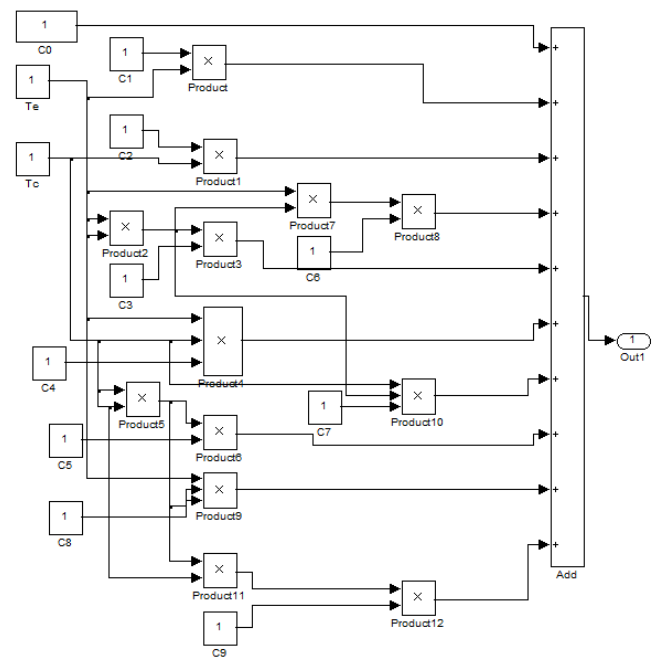

Figure 4. Simulink model of

Total power consumption of DXAC

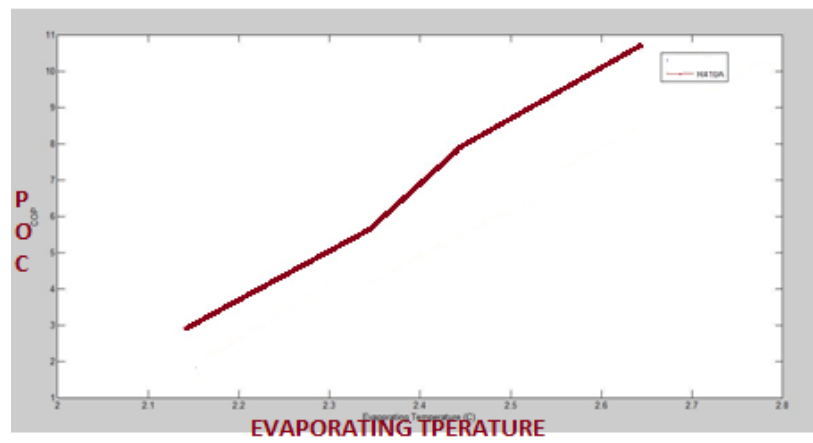

Figure 5 Variation of COP with Evaporator Temperature

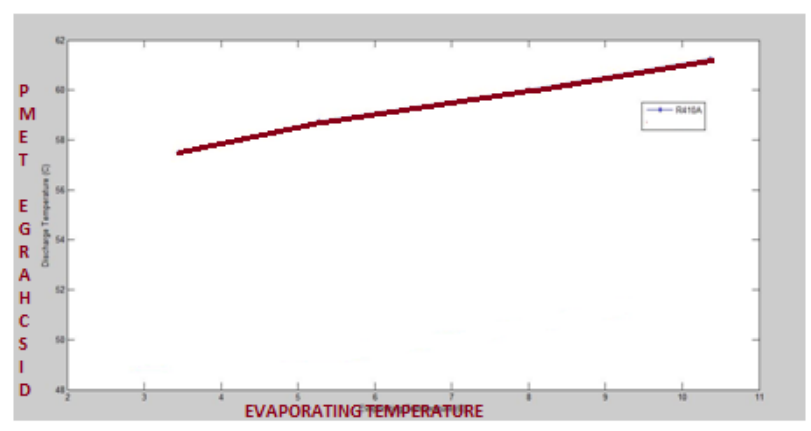

Figure 6 Evaporator temperature vs discharge temperature

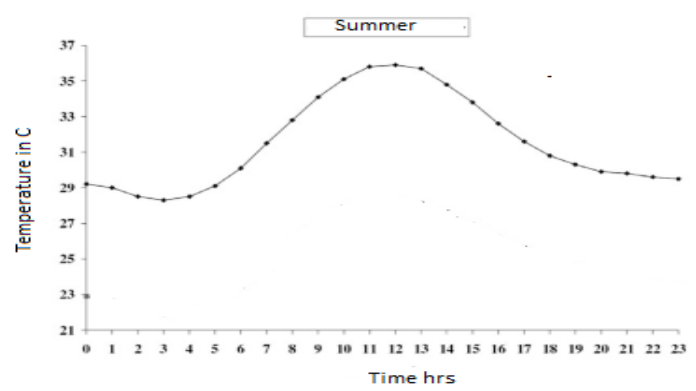

Figure 7.Outdoor temperature variation

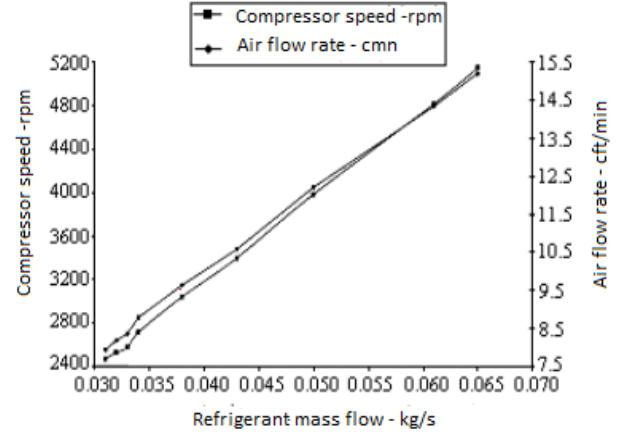

Figure 8. Variation of refrigerant mass flow rate

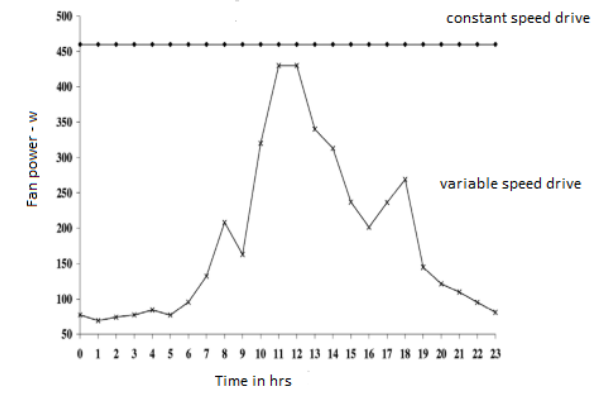

Figure 8. Power consumption during compression

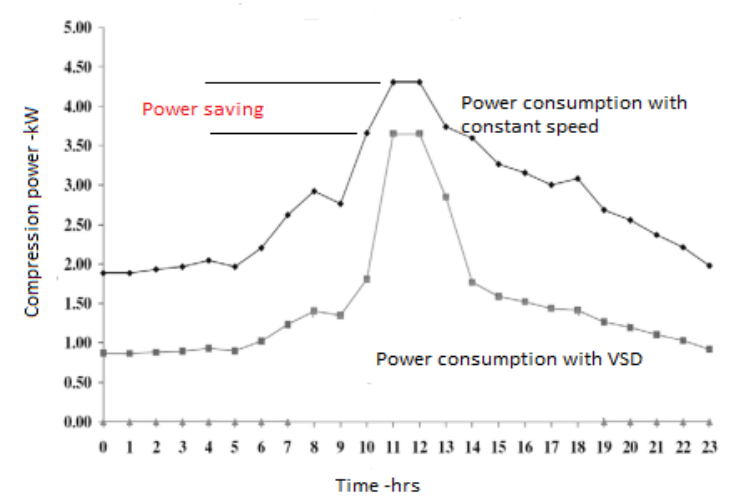

Figure 8. Power consumption during compression

\subsection{Results and discussions}

In this research work optimization through modeling and simulation is addressed using MATLAB tool for empirically based regression analysis using available data. Power consumption in DXAC is a function of temperature, humidity and space cooling load which is expressed in equations used during modeling. The R-squared value of the model was 0.96 , indicating a good fit. This study is for a commercial space in composite climates, shows effectiveness of the method adopted in DXAC system for small and medium scale office buildings. Statistical software in MATLAB was used to calculate the coefficients of the quadratic cost function. The regression process explains the coefficients in terms of variations in the actual overall system energy consumption. $\mathrm{R}^{2}$ value was found to be 0.96 which is satisfactory

ASHRAE standard 55 recommends $23 \quad-27^{0} \mathrm{C}$ temperature and $50-60 \%$ relative humidity for summer comfort conditions. Results show that the minimum, maximum and average values of the indoor temperature 
after optimization are well within prescribed limits. Hence the indoor temperature and humidity will be in the comfort ranges.

\section{Conclusions}

1. There is an improved performance in terms of both power saving and thermal comfort.

2. Adoption of variable speed drive system has been identified as one of the most promising energy saving technologies having abundant research and development opportunities

3. Power saving around $11.6 \%$ by using VSD for compressor

4. Power saving was attributed to control of refrigerant mass flow in the evaporator and regulated fan and compressor speed to match the load requirement.

5. Mass flow of refrigerant modulated from $0.03 \mathrm{~kg} / \mathrm{s}$ to $0.065 \mathrm{~kg} / \mathrm{s}$ by varying compressor $\mathrm{rpm}$ to match evaporator temperature

6. Air flow rate requirement varied between $7.93 \mathrm{cmm}$ to $15.03 \mathrm{cmm}$

7. The mass flow rate of refrigerant having a direct relation with compressor speed.

\section{References}

Perez-Lombard, L., Ortiz, J., and Pout, S, A Review on Building Energy Consumption Information, Energy and Building, Vol. 40, pp. 394-398, 2008.

Ana Paula Batista et al., optimization of the operation of an airconditioning system by Means of a distributed control system, proceedings: Building Simulation p 457-464, 2007

Li, Z., Deng, S., An Experimental Study on the Inherent Operational Characteristics of a Direct Expansion (DX) Air Conditioning (A/C) Unit, Energy and Building, Vol. 40, pp. 394-398, 2008

Freitas, M. E. A, Energy management in a direct expansion air conditioning unit Modeling, Simulation and Control (in portuguese). PhD. Qualifying Monography, Federal University of Minas Gerais, Brazil-105 pages,2007
Qureshi, T., \& Tassou, S. A, Variable speed capacity control in refrigeration. Applied Thermal Engineering , Vol. 16, No. 2, pp. 103-1, 1996

Braun, J.E., Klein, S.A., Beckman, W.A., and Mithchell, J.W, Methodology for Optimal Control of Chilled Water Systems Without Storage, ASHRAE Transactions, Vol. 95(1), pp. 652662, 1989

Ahn, B.C., and Mitchell, J.W, Optimal Control development for Chilled Water Plants Using a Quadratic Representation, Energy and Buildings, Vol. 33, pp. 371-378, 2001

Yao, Y., Lian, Z., Hou, Z, and Zhou, X, Optimal operation of a large cooling system based on an empirical model, Applied Thermal Engineering, Vol. 24, 2303-2321, 2004

Huh, J.H., and Brandemuehl, M.J, Optimization of AirConditioning System Operating Strategies for Hot and Humid Climates, Energy and Building, Vol. 40, pp. 1202-1213, 2008

Ghaddar, N., Mossolly, M., and Ghali, K, Optimal Control Strategy for a Multi-Zone Air Conditioning System Using a Genetic Algorithm, Energy, Vol. 34, pp. 58-66, 2009

Yan, Y., Zhou, J., Lin, Y., Yang, W., Wang, P., and Zhang, G, Adaptive optimal control model for building cooling and heating sources, Energy and Building, Vol. 40, pp. 1394-1401, 2008

MATLAB, Mathworks Inc, 2010

ASHRAE Inc, ASHRAE Standard 55: thermal environment conditions for Human Occupancy, 2004

Kulkarni, M. R. and Hong, F., Energy optimal control of a residential space-conditioning system based on sensible heat transfer modeling. Building and Environment, pp. 31-38, 2004

Lin, J. L. and Yeh, T.J., Modeling, identification and control of air conditioning systems, International journal of Refrigeration, pp. 209-220, 2007

Zhifang, X., Lin, S., and Hongfei, O., Refrigeration Flow Characteristics of Electronic Expansion Valve Based on Thermodynamic Analysis and Experiment, Applied Thermal Engineering, Vol. 28, pp. 238-243, 2008

Air-Conditioning and Refrigeration Institute, ARI Standard 5401999 Positive Displacement Refrigerant Compressor Equipment, Arlington, VA, 1999 